(C) 1983. The Genetical Society of Great Britain

\title{
FREQUENCY AND SELECTION IN THE INDUSTRIAL MELANIC MOTH ODONTOPTERA BIDENTATA
}

\author{
L. M. COOK* AND Th. M. G. M. JACOBS $\dagger$ \\ * Department of Zoology, University of Manchester, Manchester M13 9PL U.K. \\ $\uparrow$ Landbouwhogeschool, Generaal Foulkesweg 53, 6703 BM Wageningen, \\ The Netherlands
}

\section{SUMMARY}

Data are presented on morph frequency, selective return and date of emergence of morphs in the polymorphic melanic moth Odontoptera (=Gonodontis) bidentata (CL.). They come from three sites along the Mersey in industrial northwest England, and are used to test predictions from an earlier survey. There has been no decline in melanic frequency over the period studied. Non-melanics returned to traps less frequently than melanics at a site where the melanic frequency is high, agreeing with an earlier result. This suggests selection against non-melanics. Emergence starts later to the east of the region than to the west, and melanics emerge later than non-melanics. The late emergers must include heterozygotes as well as homozygotes. These results are discussed in relation to the question of how the polymorphism is maintained.

\section{INTRODUCTION}

The Scalloped hazel moth, Odontoptera (= Gonodontis) bidentata $(\mathrm{Cl}$.$) has$ a melanic form nigra which reaches a high frequency in northern England. The frequency apparently increased in the nineteenth century (e.g., Wright, 1911, Bowater, 1914). In a survey in the early 1970 s it was at its highest level of 70-80 per cent in Leeds and Manchester, and declined westward along a transect from Manchester to Liverpool and Birkenhead running parallel to and north of the river Mersey (Bishop et al., 1978a). Along the transect the frequencies rise to local peaks in the industrial towns and fall in the suburban and semi-rural areas between (fig. 1). At the Manchester end there was a sharp drop in frequency from 80 per cent in central Manchester to $15-30$ per cent $15 \mathrm{~km}$ to the south in Cheshire.

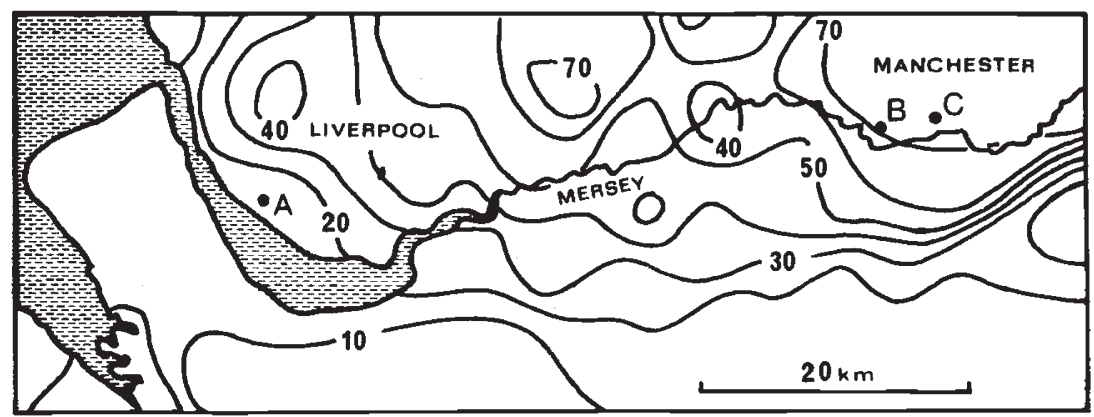

Frg. 1. Map showing the Mersey valley with the positions of Liverpool and Manchester. Contours represent per cent nigra morph in the moth $O$. bidentata estimated by Bishop et al., 1978a. The sites discussed in the present paper are A: Aigburth, B: Didsbury, C: Heaton Moor. 
The pattern suggests that the dark morph is an industrial melanic, directly affected by conditions in the old, and at one time heavily polluted, industrial centres. It has a pattern of distribution corresponding more closely with these sites than that of the Peppered moth Biston betularia, which has a melanic frequency of over 90 per cent throughout the region. Unlike the Peppered moth, however, it appears to be secretive in its resting behaviour and therefore less likely to be exposed to selective predation (Bishop et al., 1975, but cf. Mikkola, 1983, who considers that the role of selective predation may have been over-emphasized in $B$. betularia).

When trying to find clues as to the factors maintaining the polymorphism (Bishop et al., 1978a) we made the following observations. The average distance of movement appears to be much lower than that of the Peppered moth. There is less evidence of selective elimination on adults than in the Peppered moth, although the average rate of returns of typicals did appear to be lower than that of melanics in Manchester, where the melanic frequency was high. Date of emergence of adults was on average later in Manchester than further west in Warrington and Liverpool, where the frequencies of nigra were lower. This will have the effect of reducing gene flow between neighbouring areas. In Manchester the date of emergence appeared to be bimodal, the second mode having the higher frequency of melanics, and we speculated that this contained most of the nigra homozygotes.

Since the time of the survey the amount of smoke pollution of the atmosphere has progressively declined. Corresponding declines in melanic frequency have been recorded in $B$. betularia in and to the south of Birmingham (Lees, 1981) and in the same species on the Wirral peninsula (Clarke and Sheppard, 1966, Whittle et al., 1976, summarised by Bishop and Cook, 1980).

We now have additional records for $O$. bidentata collected over several years in Manchester by L.M.C. and J. Delf, and in Liverpool by the late J. A. Bishop and T. J. These have been examined for evidence of change in morph frequency with time and for confirmation or otherwise of selective elimination and of differential emergence time of the morphs.

\section{MATERIALS AND METHODS}

Moths were collected at two sites in the Manchester area and one in Liverpool. In Manchester these were at Heaton Moor (National Grid Reference 33 882918) and Didsbury (Nazarene College, G.R. 33 840910), and in Liverpool at Aigburth (G.R. 33 388857). All the sites lie just north of the Mersey valley (fig. 1). In the first survey these sites produced nigra frequencies of 68 per cent at Heaton Moor, from a small sample of 19 individuals in 1972, 67 per cent at Didsbury in $1974(N=306)$ and 12 per cent at Aigburth from 1971-75 $(N=923)$. Trapping was by assembling trap using caged females to attract males, or occasionally by mercury vapour light trap. Light traps are very much less efficient than assembling traps for this species, the difference in efficiency being greater than in B. betularia. The numbers caught varied greatly from year to year. Whenever possible insects were scored, marked and released. Recaptures were used to estimate population size and survival rate. 


\section{RESUlts}

(i) Frequency in successive years

The total numbers caught throughout the collecting period are shown in table 1. There is no evidence of a trend in frequency at any of the sites.

TABLE 1

Numbers of nigra and non-nigra individuals of the moth Odontoptera bidentata caught in successive years at three sites along the Mersey valley

\begin{tabular}{lrrrc}
\hline \multicolumn{1}{c}{ Site } & Year & nigra & non-nigra & per cent nigra \\
\hline Heaton Moor & 1972 & 13 & 6 & $68 \cdot 4$ \\
& 1977 & 85 & 56 & $60 \cdot 3$ \\
& 1978 & 438 & 186 & $70 \cdot 2$ \\
& 1979 & 108 & 41 & $72 \cdot 5$ \\
& 1980 & 110 & 46 & $70 \cdot 5$ \\
& 1981 & 3 & 4 & $42 \cdot 8$ \\
Didsbury & 1982 & 35 & 19 & $64 \cdot 8$ \\
& & & & \\
& 1974 & 182 & 95 & $65 \cdot 7$ \\
& 1979 & 109 & 47 & $69 \cdot 9$ \\
Aigburth & 1981 & 154 & 109 & $68 \cdot 6$ \\
& 1982 & 32 & 15 & \\
& & & & $11 \cdot 4$ \\
& 1971 & 4 & 31 & $14 \cdot 9$ \\
& 1972 & 7 & 40 & $12 \cdot 1$ \\
& 1973 & 33 & 239 & $10 \cdot 7$ \\
& 1974 & 67 & 421 & $12 \cdot 5$ \\
& 1975 & 14 & 117 & $14 \cdot 9$ \\
& 1977 & 41 & 286 & $16 \cdot 4$ \\
& 1978 & 71 & 404 & $12 \cdot 0$ \\
\hline
\end{tabular}

In order to test this, taking into account changes in sample size from year to year the method used by Lees and Creed (1975) and in the earlier survey was employed. Values of $\chi^{2}$ were calculated for the $2 \times 2$ tables representing pairs of successive years. The signed square root of $\chi^{2}$ was then found, which is a normal deviate indicating whether a significant increase or decrease has occurred. Only two of these values were significant (Heaton Moor, 1977-78, $\chi=2 \cdot 29$ and Didsbury, 1979-81, $\chi=-2 \cdot 32$ ). The 17 values were summed, squared and divided by 17 to give a $\chi^{2}$ value of 0.016 ( $\mathrm{df}=1, P>0.9$ ). There is therefore no evidence of a progressive change in morph frequency. No change was seen in the earlier survey, where 26 sites were compared over time intervals of a year or two. There is also no indication from the data that the difference in frequency between the sites may be declining. Similarly, Lees (1981) found no consistent decline in the frequency of melanics in the moth Phigalia pilosaria on a transect where the frequency of melanic $B$. betularia had declined.

\section{(ii) Selection on adults}

Where animals were marked and released recapture data are obtained, which may be tested for differential return of the moths. The recapture 
results have been analysed by the method of Manly (1973) to produce estimates of the fitness of non-nigra relative to nigra. Previously, results were obtained for three sites in Liverpool and two in Manchester. Estimates are now available for later years at the Aigburth site in Liverpool and for Heaton Mersey and Didsbury. They are presented together with the earlier ones in table 2. The combined estimate at Heaton Moor was obtained by adding the small amount of information available for 1977, 1979 and 1982 to the large sample for 1978 .

\section{TABLE 2}

Estimates of selective recapture for sites in Liverpool and Manchester. The fitness of non-nigra relative to nigra is shown, calculated by the method of Manly (1973). Data marked with an asterisk have been published previously.

\begin{tabular}{|c|c|c|c|c|}
\hline Site & Year & per cent nigra & Fitness & Standard error \\
\hline \multirow[t]{7}{*}{ Aigburth } & $1974^{*}$ & 13.7 & $1 \cdot 34$ & 0.22 \\
\hline & $1975^{*}$ & $10 \cdot 7$ & 0.83 & $0 \cdot 10$ \\
\hline & 1977 & $12 \cdot 5$ & 1.02 & $0 \cdot 16$ \\
\hline & 1978 & 14.9 & 0.8 & 0.14 \\
\hline & 1979 & $16 \cdot 4$ & $3 \cdot 46$ & $2 \cdot 08$ \\
\hline & 1980 & $12 \cdot 0$ & $1 \cdot 28$ & 0.35 \\
\hline & combined & $13 \cdot 8$ & 0.99 & 0.07 \\
\hline Cressington Park & $1970^{*}$ & $15 \cdot 6$ & 0.89 & 0.06 \\
\hline Groadgreen & $1969^{*}$ & $44 \cdot 6$ & 0.98 & $0 \cdot 12$ \\
\hline Wythenshawe & $1974^{*}$ & $47 \cdot 1$ & $1 \cdot 06$ & 0.05 \\
\hline Didsbury & 1981 & 58.6 & 0.94 & 0.13 \\
\hline \multirow[t]{2}{*}{ Heaton Moor } & 1978 & $70 \cdot 2$ & 0.77 & $0 \cdot 15$ \\
\hline & $1977-82$ & 68.9 & $0 \cdot 82$ & $0 \cdot 14$ \\
\hline Rusholme & $1973^{*}$ & $79 \cdot 5$ & 0.74 & 0.11 \\
\hline
\end{tabular}

The Aigburth data have been tested for heterogeneity by summing the $\chi^{2}$ values from each year and taking from the sum the $\chi_{1}^{2}$ calculated as we have done' above. This provides $\chi_{5}^{2}=9 \cdot 06$, which is not significant. The data have therefore been pooled by a method given by Manly (1972) to give a combined estimate of 0.99 . Using this value for Aigburth, there is only one site in the seven for which the estimate is greater than unity (Wythenshawe) and only one which is significantly dfferent from unity (Rusholme; $\chi_{1}^{2}=6.07, P<0.05$ ). Combining the data to test the trend produces $\chi_{1}^{2}=3.91$, which is just significant at the 5 per cent level. For the heterogeneity test, $\chi_{6}^{2}=8.35(P>0.05)$. We conclude, tentatively, that the data show overall slight selection against typicals, although this is mostly due to the large effect at Rusholme.

\section{(iii) Date of emergence}

Data on numbers trapped per day are available at Aigburth and Heaton Moor for four years from 1977 to 1980 . Recording of day of capture commences on 18 May each year except 1980 , a leap year, when it starts on 17 May. The pattern of emergence usually involves a rapid increase in numbers over the first ten days, followed by a slower decline, so that there is a tail of emergence extending into July. It was suggested (Bishop et al., $1978 a$ ) that the tail may in fact contain a second peak of emergence. This 
is difficult to detect, however, and in comparing the sites we have transformed the data by taking the logarithm of the day of emergence in order to make allowance for the assymetry of the distribution. The values shown in table 3 are obtained. Analysis of variance shows that the difference in emergence time between sites is very significant $(F=2188 \cdot 6)$, but that there is also significant variation between years $(F=820 \cdot 6)$. The annual pattern of emergence shows some resemblance between sites, 1980 being the most advanced season of the four.

TABLE 3

Mean and 95 per cent confidence intervals for data of emergence at two sites, based on the logarithm of day of emergence. The first day scored is 18 May for 1977-79 and 17 May for 1980.

\begin{tabular}{lccc}
\hline \multicolumn{1}{c}{ Site } & Year & Mean & Confidence intervals \\
\hline Aigburth & 1977 & $10 \cdot 5$ & $4 \cdot 3-25 \cdot 6$ \\
& 1978 & 12.9 & $4 \cdot 0-41 \cdot 4$ \\
& 1979 & $21 \cdot 9$ & $9 \cdot 9-45 \cdot 6$ \\
Heaton Moor & 1980 & $8 \cdot 5$ & $2 \cdot 5-28 \cdot 7$ \\
& 1977 & $26 \cdot 7$ & $12 \cdot 9-55 \cdot 6$ \\
& 1978 & $20 \cdot 9$ & $10 \cdot 3-42 \cdot 2$ \\
& 1979 & 28.6 & $14 \cdot 7-55 \cdot 3$ \\
& 1980 & $16 \cdot 0$ & $4 \cdot 1-63 \cdot 4$ \\
\hline
\end{tabular}

The proposition we suggested was that the later emergence in Manchester was due, in part at least, to the later emergence of nigra individuals, which are at a higher frequency there, and in particular to late emergence of nigra homozygotes. In order to examine this we may compare the frequency of nigra and non-nigra in the first three-quarters of the season's emergence, as compared with the final quarter. When that is done for the published data from 1973 to 1975 the frequency of nigra is higher in the last quarter in eight out of nine cases. The overall tendency for the final quarter to have a higher frequency of nigra is very significant $\left(\chi_{1}^{2}=\right.$ 10.54). These results are shown in table 4.

The later results also indicate that nigra emerges later than non-nigra (table 4). For the five sets of data for the Manchester area the $\chi_{1}^{2}$ measuring the trend is $2.05(P>0.1)$. For Aigburth the equivalent value is 3.09 . Combining these data from the two areas we get $\chi_{1}^{2}=5 \cdot 02$, which is significant $(P<0 \cdot 05)$. It may be argued that since we are interested in testing whether the frequency increases, rather than that it deviates, the one-tailed criterion should be used. The significance of the difference would be increased. If nigra were selected then its frequency might go up progressively through the season. This would not account, however, for the higher frequency of the melanics at the end of the season at Aigburth.

The suggestion that emergence is bimodal is difficult to confirm or to contradict, owing to the erratic nature of the capture pattern from day to day. This irregularity is almost certainly a consequence in part of fluctuation in weather conditions. Even in the largest set of results, for 1978, the pattern may be bimodal but is not certainly so. The data are therefore not presented here. 
TABLE 4

Totals for nigra and non-nigra caught in the first three-quarters and the final quarter of the emergence in each season. Results in the upper part of the table are from the earlier survey.

\begin{tabular}{|c|c|c|c|c|c|c|c|}
\hline \multirow[b]{2}{*}{ Site } & \multirow[b]{2}{*}{ Year } & \multicolumn{3}{|c|}{ 1st three-quarters } & \multirow[b]{2}{*}{ nigra } & \multicolumn{2}{|l|}{ final quarter } \\
\hline & & nigra & non-nigra & $\%$ nigra & & non-nigra & $\%$ nigra \\
\hline \multirow[t]{2}{*}{ Aigburth } & 1974 & 47 & 363 & $11 \cdot 5$ & 5 & 26 & $16 \cdot 1$ \\
\hline & 1975 & 8 & 98 & $7 \cdot 5$ & 6 & 30 & $16 \cdot 7$ \\
\hline Warrington & 1973 & 53 & 47 & $53 \cdot 0$ & 16 & 8 & $66 \cdot 7$ \\
\hline Chorltonville & 1974 & 65 & 25 & $72 \cdot 8$ & 11 & 7 & $61 \cdot 1$ \\
\hline \multirow[t]{2}{*}{ Wythenshawe } & 1974 & 223 & 277 & $44 \cdot 6$ & 84 & 67 & $55 \cdot 6$ \\
\hline & 1975 & 43 & 60 & $41 \cdot 7$ & 7 & 4 & 63.6 \\
\hline Didsbury & 1974 & 145 & 83 & $63 \cdot 6$ & 59 & 19 & $75 \cdot 6$ \\
\hline \multirow[t]{2}{*}{ Rusholme } & 1973 & 109 & 32 & $77 \cdot 3$ & 88 & 18 & $83 \cdot 0$ \\
\hline & 1974 & 75 & 22 & $77 \cdot 3$ & 47 & 12 & $79 \cdot 7$ \\
\hline Didsbury & 1979 & 81 & 39 & $67 \cdot 5$ & 28 & 8 & $77 \cdot 8$ \\
\hline \multirow[t]{4}{*}{ Heaton Moor } & 1977 & 60 & 41 & $59 \cdot 4$ & 25 & 15 & $62 \cdot 5$ \\
\hline & 1978 & 316 & 145 & $68 \cdot 5$ & 119 & 38 & $75 \cdot 8$ \\
\hline & 1979 & 78 & 31 & $71 \cdot 6$ & 30 & 10 & $75 \cdot 0$ \\
\hline & 1980 & 85 & 34 & $71 \cdot 4$ & 25 & 12 & 67.6 \\
\hline \multirow[t]{4}{*}{ Aigburth } & 1977 & 28 & 222 & $11 \cdot 2$ & 16 & 64 & 16.9 \\
\hline & 1978 & 49 & 312 & $13 \cdot 6$ & 22 & 92 & $19 \cdot 3$ \\
\hline & 1979 & 38 & 223 & $14 \cdot 6$ & 23 & 87 & 20.9 \\
\hline & 1980 & 42 & 287 & 12.8 & 11 & 100 & 9.9 \\
\hline
\end{tabular}

\section{Discussion}

The maintenance of polymorphism in industrial melanics is not fully understood. The correlation of mealanic frequency with areas of industrialisation indicates that selection favouring melanics acts in these areas. In $B$. betularia the fact that the insect almost certainly spends part of its life on exposed surfaces during the day, the evidence from artificial selection experiments and the decline in melanic frequency after introduction of smoke control all suggest that visual predation plays a part. Mani (1982) developed a theoretical model in which visual selection, non-visual difference in fitness between melanics and non-melanics (demonstrated by Creed et al., 1980), and migration (demonstrated by Bishop, 1972) combine to produce a plausible representation of the known geographical pattern of morph frequency.

In $O$. bidentata it is known that the moths tend to be more secretive in their resting position (Bishop et al., 1975). Nevertheless, experiments indicated that non-nigra individuals were at a disadvantage in areas of high nigra frequency, and there is evidence of late emergence of nigra (Bishop et al., $1978 a, b)$. We therefore proposed as a tentative hypothesis that non-nigra suffers selective predation in urban industrial areas, probably at a lower level than Biston, and that nigra homozygotes emerge later than the rest of the population. The homozygotes would then have a more limited choice of mates. If the time gap were right, they would be at a mating disadvantage, because some were unable to obtain mates. Migratory powers appear to be much weaker than in Biston. This pattern of selection and migration could account for the fact that in $O$. bidentata the frequency varies over smaller distances than in Biston. Mani (1981) has investigated the general properties of systems with a time lag in emergence of one 
morph. If balance is achieved in this way then, just as spatial pattern is on a smaller scale than in Biston, so it might be expected that morph frequency should change more rapidly when environmental changes modify the selective pattern.

The results discussed here were collected to test the model outlined above. The model is neither completely endorsed nor contradicted. There is no change in frequency with time. On the other hand, tests for selection produced apparent selection against non-nigra at a second site (Heaton Moore) at which nigra is at a high frequency, the level of selection being very similar to that observed before at Rusholme. There is confirmation that nigra makes up a larger fraction of the later than of the earlier emergence period. This is true in Liverpool, however, where nigra homozygotes are 1 per cent or less of the population, as well as in Manchester where they are a substantial minority. The later period must therefore contain heterozygotes as well as melanic homozygotes, although not necessarily in random proportions. Late emergence was discussed by Mani (1981) on the assumption that the delayed section was homozygous. The effects of differential emergence are complex, however, depending on the length of the delay, assymetry in delay between the sexes and the effect it has on mating behaviour. It is possible that the emergence pattern plays a part in generating the differences in frequency distribution between $O$. bidentata and $B$. betularia.

Note added in proof: For 1983 at Heaton Moor, there were 111 nigra: 46 non-nigra, giving a melanic frequency of $70 \cdot 7 \%$.

Acknowledgements. We are grateful to Sir Cyril Clarke and Drs D. R. Lees, G. S. Mani, $\mathrm{K}$. Mikkola and J. Muggleton for comments on this paper. The collaboration on which it is based began when Jacobs spent a post-doctoral year in Liverpool with J. A. Bishop. He thanks his parents for the support which made this visit possible. Mr J. Delf kindly made available the data from Didsbury for 1981 and 1982.

\section{REFERENCES}

BISHOP, J. A. 1972. An experimental study of the cline of industrial melanism in Biston betularia (L.) (Lepidoptera) between urban Liverpool and rural North Wales. J. anim. Ecol., 41, 209-243.

BISHOP. J. A. AND COOK, L. M. 1980. Industrial melanism and the urban environment. Adv. ecol. Res., 11, 373-404.

BISHOP, J. A., COOK, L. M. AND MUGGLETON, J. 1978a. The response of two species of moths to industrialization in northwest England. I. Polymorphism for melanism. Phil. Trans. Roy. Soc. Lond. B., 281, 489-515.

BISHOP, J. A., COOK, L. M. AND MUGGLETON, J. 1978b. The response of two species of moths to industrialization in northwest England. II. Relative fitness of morphs and population size. Phil. Trans. Roy. Soc. London. B., 281, 517-542.

BISHOP, J. A., COOK, L. M., MUGGLETON, J. AND SEAWARD, M. R. D. 1975. Moths, Lichens and air pollution along a transect from Manchester to North Wales, J. appl. Ecol., 12, 83-93.

BOWATER, W. W. 1914. Heredity of melanism in Lepidoptera. J. Genet., 3, 299-315.

CLARKE, C. A. AND SHEPPARD, P. M. 1966. A local survey of the distribution of industrial melanic forms in the moth Biston betularia and estimates of the selective values of these in an industrial environment. Proc. Roy. Soc. Lond., B., 165, 424-439.

CREED, E. R., LEES, D. R. AND BULMER, M. G. 1980. Pre-adult viability differences of melanic Biston betularia (L.) (Lepidoptera). Biol. J. Linn. Soc., 13, 215-262. 
LEES, D. R. 1981. Industrial melanism: genetic adaptation of animals to air polution. In Bishop, J. A. and Cook, L. M. (ed.) Genetic Consequences of Man Made Change, Academic Press, London.

LEES, D. R. AND CREED, E. R. 1975. Industrial melanism in Biston betularia: the role of selective predation. J. anim. Ecol., 44, 67-83.

MANI, G.S. 1981. Conditions for balanced polymorphism in the presence of differential delay in developmental time. Theoret. pop. Biol., 20, 363-393.

MANI, G. S. 1982. A theoretical analysis of the morph frequency variation in the peppered moth over England and Wales. Biol. J. Linn. Soc., 17, 259-267.

MANLY, B. F. J. 1972. Estimating selective values from field data. Biometrics, 28, 1115-1125.

MANLY, B. F. J. 1973. A note on the estimation of selective values from recaptures of marked animals when selection pressures remain constant over time. Res. pop. Ecol., 14, 151-158. MIKKOLA, K. 1983. Biol. J. Linn. Soc. in press.

WHITTLE, P. D. J., CLARKE, C. A., SHEPPARD, P. M. AND BISHOP, J. A. 1976. Further studies on the industrial melanic moth Biston betularia (L.) in the northwest of the British Isles. Proc. Roy. Soc. Lond. B., 194, 467-480.

WRIGHT, A. E. 1911. Macrolepidoptera of N.E. Lancashire. Rep. Manchester Ent. Soc., 9, $25-44$. 